nadir of $2.0 \mathrm{~L}(52 \%$ fall) and bronchodilator therapy was administered (Figure). Histamine responsiveness $24 \mathrm{~h}$ post challenge increased with a PC 20 of $3.3 \mathrm{mg} / \mathrm{ml}$. The active challenge was not repeated.

Conclusion We demonstrated an isolated sustained late asthmatic reaction to the ER system confirming OA. The likely sensitiser was cyclohexylamine (an aliphatic amine hardener) which had a high "Chemical Asthma Hazard Assessment Score" of 0.9283. To ensure patient safety, it is important to be aware of this pattern of response (which is typical of low molecular weight agents). It also explains why the patient did not closely link his symptoms with work. The exact immunological mechanisms are not currently known.

\section{M5 THE CORRELATION BETWEEN SATISFACTION WITH INFORMATION ABOUT MEDICINES AND CLINICAL OUTCOMES IN AN ETHNICALLY DIVERSE DIFFICULT ASTHMA COHORT}

H Dhruve, H Khachi. Bart's Health NHS Trust, London, UK

10.1136/thoraxjnl-2016-209333.447

Introduction It is thought that a common cause of poor asthma control is lack of information about medication and their use. This study aims to investigate the influence of satisfaction with information about medicines and its associated clinical outcomes in patients in a difficult asthma cohort.

Methodology Ethics approval was granted. All patients attending a difficult asthma clinic in a large tertiary centre were invited to participate. The Satisfaction with Information about Medicines Scale (SIMS) questionnaire was used. ${ }^{1}$ This validated 17 item questionnaire, explores various aspects of medication information with preventer inhalers and the associated patient satisfaction with this. Demographic and adherence information from the GP were also collected. SPSS version 22.0 was used to analyse the data.

Results The table shows that patients from non-Caucasian backgrounds had statistically significantly lower reported satisfaction with information about medicines. There was also a statistically significant correlation between low satisfaction with information and increased salbutamol use and rates of asthma exacerbations.

Discussion This study shows the importance of ethnicity to the level of satisfaction with information about medicines. Language barriers, lack of understanding or health beliefs could be contributing factors. Our study found no statistical significance found between GP prescription refill rates (adherence) and associated exacerbations and salbutamol use. However, it is worth noting that our study did not investigate whether patients who picked up their preventer inhalers were indeed using them as intended by their clinician, nor did it assess inhaler technique.

Conclusion We have shown that using a validated questionnaire can help identify patients who are at risk of having a lower satisfaction with their medicines and in turn a greater likelihood of having poorer clinical outcomes. Eliciting satisfaction with information about medication can help tailor interventions to support clinical outcomes in patients from ethnic minorities.

\section{REFERENCE}

1 Horne R, Hankins $M$, et al. The Satisfaction with Information about Medicines Scale (SIMS): a new measurement tool for audit and research. Qual Health Care 2001;10(3):135-140
Abstract M5 Table 1

\begin{tabular}{|c|c|}
\hline & $\begin{array}{l}\text { Satisfaction with information about } \\
\text { medicines Scale (SIMS) - likelihood to be } \\
\text { satisfied with preventer inhaler medication }\end{array}$ \\
\hline $\begin{array}{l}\text { Gender } \\
\text { Female }(n=49) \\
\text { Male }(n=26)\end{array}$ & No significant difference between genders found \\
\hline $\begin{array}{l}\text { Age } \\
\begin{array}{l}18-30(n=2) \\
31-50(n=35) \\
51-70(n=31) \\
70+(n=7)\end{array}\end{array}$ & No significant difference between ages found \\
\hline $\begin{array}{l}\text { Ethnicity } \\
\text { - White Caucasian ( } n=46) \\
\text { - Ethnic Backgrounds }(n=29) \\
\text { Asian }(n=21) \\
\text { Black Afro-Caribbean }(n=6) \\
\text { European }(n=2)\end{array}$ & $\begin{array}{l}\text { Satisfied }(P<0.01) \\
\text { Not satisfied }(P<0.01)\end{array}$ \\
\hline $\begin{array}{l}\geq 80 \% \text { Adherence to inhaled } \\
\text { corticosteroids (ICS) as per GP refill } \\
\text { information }\end{array}$ & $\begin{array}{l}\text { No significant correlation between satisfaction } \\
\text { and adherence found }\end{array}$ \\
\hline Salbutamol use/day & $\begin{array}{l}\text { Increased salbutamol use when not satisfied } \\
(P<0.05)\end{array}$ \\
\hline Exacerbations per year & $\begin{array}{l}\text { Increased rate of exacerbations when not } \\
\text { satisfied }(P<0.05)\end{array}$ \\
\hline
\end{tabular}

\section{M6 IMPROVING FOLLOW-UP IN PATIENTS ATTENDING AND DISCHARGED FROM ACCIDENT AND EMERGENCY WITH ASTHMA EXACERBATIONS}

WJ Newman, 0 Lamont. Forth Valley Health Board, Larbert, UK

\subsection{6/thoraxjnl-2016-209333.448}

Introduction The Respiratory and Accident and Emergency (A\&E) departments in Forth Valley audited asthma care in the emergency department over the past years. Shortcomings in a number of areas have been identified and quality improvement measures undertaken.

One area was the failure to organise follow-up for patients following attendance at A\&E, (24\% in 2009, $47 \%$ in 2012). As a result a new system was introduced.

Methods Forth Valley Health Board serves a population of 310,000 and has one acute hospital with 860 beds. The Respiratory Service comprises of 6 Consultants and 5.5 Respiratory Nurses. There are specialist asthma clinics run by the physicians/ nurses. Patients with an asthma exacerbation discharged from the $A \& E$ department are identified by interrogating the A\&E patient management system daily and clinical and contact details obtained. The Respiratory nurses contact any patient to obtain further information (standardised questionnaire) and make a management plan with the patient. Their case is then discussed with the on-call Respiratory physician and further recommendations instituted.

Results 88 cases ( 27 (30\%) male, 61 (70\%) female) were identified as having attended with an exacerbation of their asthma and discharged from A\&E during 2015. Median age 36 (range 17$78), 46(58 \%)$ presented at weekends or outwith working hours (0800-1800), 70 (80\%) were discharged home with oral steroids.

Of the 88 patients one had no telephone/one lived outside the UK. $26(30 \%)$ patients did not reply and the GP practice was 
contacted to advise of the attendance. Following discussion with the consultant it was recommended that $11(42 \%)$ continued to be managed in primary care (follow-up attendance unknown), and $15(58 \%)$ be reviewed by the Respiratory Service. 13 (86\%) attended the appointment.

$62(70 \%)$ were contactable, one was a nursing home resident (Respiratory nurses subsequently visited), one declined to answer questions. 35 (39\%) had already made an appointment to see their general practitioner. Following discussion one patient was re-admitted (same day), 30 (48\%) patients continued to be managed in primary care (follow-up attendance unknown) and 31 $(50 \%)$ were reviewed by the Respiratory service. 27 (87\%) attended the appointment.

Conclusions The introduction of a telephone conversation/management plan improves follow-up of patients with asthma exacerbations discharged from $A \& E$.

\section{\begin{tabular}{l|l} 
M7 & DESIGNING AROUND PLACEBO INHALER DEVICE
\end{tabular} CONCERNS AND IMPROVING ASTHMA HEALTHCARE PROFESSIONAL PATIENT TRAINING}

MJ Sanders, R Bruin. Clement Clarke International Ltd, Harlow, UK

\subsection{6/thoraxjnl-2016-209333.449}

Introduction Effective asthma control with drug therapy delivered via pressurised metered dose inhalers (pMDIs) is critically dependent on good inhaler technique. Healthcare professionals (HCPs) dedicate significant time and resources to patient education and review sessions, which tend to focus on the co-ordination of pMDI actuation with the slow inspiratory breath. Tools exist to facilitate this experience: dummy pMDIs, add-on devices which whistle at the ideal inspiratory flow rate and the highly valued but difficult-to-obtain placebo pMDIs. The latter currently offer the closest real-life training experience but are hampered by the multiple-use concerns of cross-infection (or confident decontamination), HCP-only demonstration, and unnecessary exposure to fluorocarbon propellants. The alternative of training with the active pMDI raises the issues of overdosing and drug wastage.

Methods Our self-imposed project brief was to design an improved low-cost solution to the placebo/drug pMDI training conundrum which included patient participation as an absolute, the ability of the HCP to visually assess technique, avoidance of contamination, and compatibility with different actuator formats; and specifically excluded, for example, validation and implementation of new decontamination techniques.

Results The solution is an add-on device, confirmed to fit all UK active and placebo pMDIs. The device (Figure 1, Flo-Checkä) is inserted into the pMDI actuator mouthpiece orifice and completely occludes the aerosol path. The lip-guard feature prevents mouth-contact contamination of the actuator and, when the patient inhales, inspiratory air is drawn in via side vents engineered to mimic the general resistance of a pMDI.

Conclusions A survey of manufacturer-supplied respiratory support devices in relation to all UK inhaled products (London Medicines Evaluation Network, 2013) revealed an almost universal lack of product specific devices with the exception of the Accuhalerâ (Glaxo Group Limited) and Symbicortâ (AstraZeneca AB) training whistles; neither of which addresses the issues raised above. Several specific placebo pMDIs are available but the pharmaceutical industry is cognizant of fluorocarbon use justification, the danger of misinterpretation as an active product, and manufacturing a low volume high unit-cost product. It is hoped that developments such as the Flo-Check address some of the issues: for manufacturer, patient and HCP.

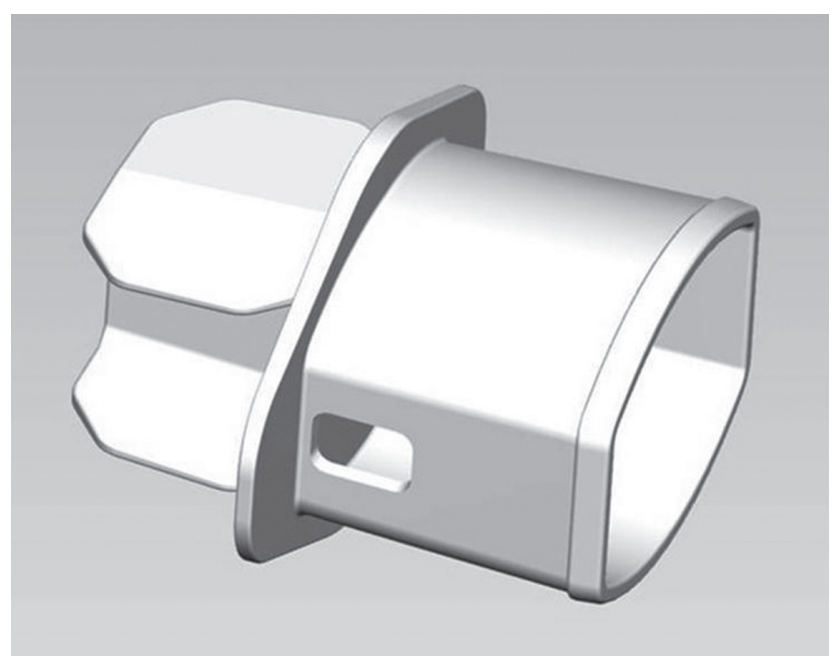

Abstract M7 Figure 1 Flo-Check device

\section{M8 ASTHMA MANAGEMENT IN AN INNER-CITY TEACHING HOSPITAL EMERGENCY DEPARTMENT: REAL-LIFE AFTER NATIONAL REVIEW OF ASTHMA DEATHS (NRAD)}

FR Ali, Z Mangera, A Downes, S Obaray. Barts Health NHS Trust, London, UK

\subsection{6/thoraxjnl-2016-209333.450}

Background The National Review of Asthma Deaths (NRAD) made multiple recommendations in the form of quality indicators linked to improving care of asthma patients in light of a review of all asthma deaths. ${ }^{1}$ We undertook an audit to establish the degree to which a busy Emergency Department in inner London adheres to these.

Method Patients admitted in the month of June 2015 with an asthma related admission were identified via the coding department. This list was reviewed to include those patients confirmed to have an acute asthma admission and seen and discharged directly from the ED department (including the short stay ED ward). The electronic records of those included were reviewed using a data collection form relating to the NRAD quality indicators.

Results A total of 42 patients were included. Our findings included the following: $83 \%$ had mild or moderate severity, the remainder having acute-severe. Almost one third of patients did not have their peak flow documented on arrival, $76 \%$ did not have their usual best or predicted best documented and 66\% did not have a discharge peak flow documented. There was no documentation if any patient had been provided with a personal asthma action plan (PAAP). Checking of inhaler technique was only documented for $14 \%$ of patients. One third of patients were presenting for the 2 nd or more time with acute asthma. Finally only 3 patients had a recommendation for GP follow up but no timeframe was suggested.

Discussion Simple measurements and interventions were omitted in a significant number of patients, highlighting the need for improvement. Some of these were straightforward such as more meticulous recording of peak flow. Others may have reflected lack of competency in the healthcare professional e.g. inhaler 